\title{
Time Discounting over the Lifespan
}

\author{
Daniel Read ${ }^{1}$ and N. L. Read \\ ${ }^{1}$ Department of Operational Research, London School of Economics
}


First published in Great Britain in 2004

by the Department of Operational Research

London School of Economics and Political Science

Copyright $@$ The London School of Economics and Political Science, 2004

The contributors have asserted their moral rights.

All rights reserved. No part of this publication may be reproduced, stored in a retrieval system, or transmitted in any form or by any means, without the prior permission in writing of the publisher, nor be circulated in any form of binding or cover other than that in which it is published.

Typeset, printed and bound by:

The London School of Economics and Political Science

Houghton Street

London WC2A 2AE

Working Paper No: LSEOR 04.63

ISBN No: 0753016850 


\begin{abstract}
Several theories of intertemporal choice predict systematic age differences in the rate at which people discount the future. Different theories, however, predict different patterns: One predicts that discounting will decrease over the lifespan, so that young people will discount more than the middle aged or elderly, another suggests it will increase over the lifespan, and yet another suggests that the middle-aged will discount less than either the young or the old. We conduct a study testing these predictions. 123 respondents between the ages of 19 and 89 made a large number of time discounting decisions on both computerized and paper-and-pencil questionnaires. The results suppported the view that older people discount more than younger ones, and that middle aged people discount less than either group. This finding appears to contrast with earlier work (Green, Fry and Myerson, 1994) but, as we show, our results are remarkably congruent with that study. We conclude by considering whether our results can be reconciled with the fact that young people commit more apparently impulsive acts than do the elderly.
\end{abstract}


Immediate benefits are normally preferred over delayed ones, and delayed losses over immediate ones. This preference pattern has been described using a variety of related terms including impatience, impulsiveness, positive discounting, and (for economists) a positive marginal rate of intertemporal substitution. It is generally assumed that each individual is characterized by how he or she discounts future outcomes as a function of their delay, with those we can call 'more patient' demonstrating it by their greater willingness to take larger-later rewards over smaller-sooner ones (Mischel, Shoda \& Peake, 1988; Strotz 1955).

One individual difference factor that has been the focus of much discussion is age. Everyday observation suggests that patience (or, impatience) changes over the lifespan. Young children are notorious for being unable to resist their impulses even for seconds, and teenagers are likewise thought to be always struggling against parental control, while as people get older they become increasingly willing to wait. The changes early in life are reflected in most developmental theories. Freud (1911/1959) proposed that as children grow, they become able to transform what they desire into an 'internal image' toward which they can direct their efforts - in this way they become able to disconnect their motivations from the 'here and now.' In a similar vein, Mischel, Shoda and Rodriguez (1989; c.f., Metcalfe \& Mischel, 1999) propose that children learn to transform the 'hot' thoughts associated with immediate gratification into 'cool' ones.

Such theories concern how initially id-driven children learn to wait, but do not address whether adults also change in their time preference over the lifespan. However, some recent theoretical developments in 'evolutionary economic psychology' have examined how time discounting is likely to develop over the adult years. These developments, described in the next section, are the impetus for the present paper, which provides the first systematic empirical study of whether, and how, time preference changes from young adulthood through to old age.

\section{Theoretical models}

In this section we describe three analyses of how people should discount the future as a function of age that make similar assumptions yet reach different conclusions. Underlying each account is the idea that solving the problem of why people discount the future is the same as solving the problem of how the benefits (or utility) that people obtain from consumption changes over time (c.f., Read, in press). To illustrate, consider the following standard measure of time discounting, the 'discount factor:'

$$
\delta=\left(\frac{x_{1}}{x_{2}}\right)^{\frac{1}{t_{2}-t_{1}}}
$$

Where $x_{1}$ and $x_{2}$ are benefits that will be received at time 1 and $2\left(t_{1}\right.$ and $\left.t_{2}\right)$, and time is measured using a standard interval. The discount factor can be measured by finding a point of indifference between receiving $x_{1}$ at $t_{1}$ and $x_{2}$ at $t_{2}$. For instance, one may be indifferent between $£ 100$ now and $£ 150$ in one year, so that the measured discount factor is: 


$$
\delta=\left(\frac{100}{150}\right)^{\frac{1}{1-0}}=0.67 \text {. }
$$

How might this discount factor arise? Two broad classes of possibility have been proposed (see, Frederick, Loewenstein \& O’Donoghue, 2002; Read, in press). First, discounting is an individual taste that may have been acquired or inherited, but is not amenable to further analysis (Strotz, 1955; Fisher, 1930). This is the kind of taste with which we say there is 'no arguing.' Second, discounting is the result of maximizing utility given the fact that the utility from outcomes differs depending on when they are received, and there is uncertainty about whether they will be received at all. To illustrate, let us return to the decision maker who is indifferent between $£ 100$ now and $£ 150$ in one year. Assume this decision maker is maximizing the total utility he gets from his choices. If he receives $£ 100$ now he will experience some utility now, call this $\mathrm{u}_{0}(£ 100)$, and if he receives $£ 150$ in one year he will experience some utility then, call this $\mathrm{u}_{1}(£ 150)$. Moreover, there is some chance that he will not get the $£ 150$ - perhaps the promise will not be kept, or he will die in the interim. If we let $\mathrm{p}_{1}$ denote the probability that the delayed $£ 150$ will be received, then he is indifferent between the options because:

$$
\mathrm{u}_{0}(£ 100)=\mathrm{p}_{1} \mathrm{u}_{1}(£ 150) \text {. }
$$

That is the utility from $£ 100$ now is equal to the expected utility from $£ 150$ in one year. The observed discount factor $\delta=.67$, therefore, reflects both changes in utility and uncertainty. Modern analyses of the relationship between age and discounting are based on the idea that both uncertainty and the utility function change systematically over the lifespan.

For Rogers (1994) the utility function is defined by Darwinian fitness which means, approximately, the representation of one's genes in future populations. The central idea is that the point of indifference for an intertemporal tradeoff occurs when the later benefit increases expected fitness just as much as the earlier one. As a very rough illustration, if the same fraction of a child can be obtained by receiving $£ 100$ now or $£ 150$ in one year, then the decision maker should be indifferent between those payments. The utility function, therefore, represents the contribution to Darwinian fitness from consumption, and the discount factor represents the ratio between the expected contributions to fitness at different ages. Rogers shows how, given how fertility changes over the lifespan, there should be a consistent relationship between age and time discounting. Young adults can get the most benefit from a unit of resource, and so they should discount more than older adults, especially for short time horizons (i.e., five years or so). Older adults becoming increasingly less able to directly transform resources into offspring, and so become more willing to delay and will even choose to transfer resources to their offspring. Moreover, young children and pre-teens should discount less than younger adults, because they cannot yet produce offspring - they are better off waiting, by transferring resources to their future selves. Based on actual fertility data, Rogers concludes that young adults around age 20-30 will show a $\delta$ of approximately .95 for short-to-medium time horizons ( 5 years or so), while people 40 years and above will show a $\delta$ of .98 for the same time horizon. Most of the effect in Rogers' model occurs 
for people in their 20s and for fairly short time horizons - for more mature adults and longer time horizons Rogers anticipates a more-or-less constant value of $\delta^{l}$.

Trostel and Taylor (2001) also argue that age-related changes in the utility function determine time preference, but do so by defining the utility function differently. Rather than focusing on the direct contribution of consumption to Darwinian fitness, they argue that $\delta$ reflects the rate at which the ability to enjoy consumption changes over the lifespan ${ }^{2}$. The starting point of the argument is that over the lifespan people's capacity to undertake pleasurable activity deteriorates, meaning that $u_{i}(x)$ will be lower, for a given $x$, the later in life the evaluation is made. That is, we gain less pleasure from (say) a dollar or a chocolate the older we are. This, by itself, will not lead to any changes in discounting over the lifespan, since a constant rate of decline will lead to a constant $\delta$ throughout life. For $\delta$ to vary systematically as we age, the rate of decline in the pleasure function must be decelerating or accelerating. If it is decelerating, then $\delta$ will increase with age; while if it is accelerating, $\delta$ will decrease. Trostel and Taylor argue that, in fact, the latter is true - over the lifetime our ability to appreciate consumption decreases at an increasing rate, so that the older we are, the more we devalue future experiences. Indeed, Trostel and Taylor's theoretical analysis actually predicts that because young people get so much pleasure out of so little consumption, they may have an overall preference for delayed consumption (implying $\delta>1$ ).

Trostel and Taylor tested their theory by extracting the implicit discount rate from longitudinal consumption data. The logic of this procedure is that if people do not discount the future at all, they will consume an equal amount in every period, but if they do discount then consumption will decrease, since they are always borrowing from their future selves. Consumption that is falling at an increasing rate is, moreover, predicted by $\delta$ decreasing over the lifespan. Based on analysis of a database providing longitudinal analysis of lifetime food consumption, Trostel and Taylor argue that $\delta$ does decrease: For 20 year olds it is .96 , while for 80 year olds it is .86 .

Sozou and Seymour (2003) also take an evolutionary perspective on the problem of time discounting. They propose that during our evolutionary history two factors will have interacted to determine how we discount the future. The first is learning about the environment. Because young people don't yet know if their world is risky or safe, they are better off acting 'as if there is no tomorrow' (a phrase used by both Sozou \& Seymour and Rogers). Thus, they should try to gain all the fitness benefits they can right now. The older they get, however, the more secure they become, with the effect that uncertainty has a reduced impact on how they discount ${ }^{3}$. The second factor, however, works in the opposite direction: health and reproductive capacity as well as reproductive opportunities fall with age at an increasing rate. Just as in Trostel and Taylor's analysis, the effect of this decline is a corresponding fall in the value of $\delta$. The net effect of Sozou and Seymour's model is a curvilinear relationship between age and discounting: middle-

\footnotetext{
${ }^{1}$ Rogers' model is driven by two factors, personal fertility and a bequest motive. When personal fertility drops to 0 , the only remaining motive is the bequest motive, which changes relatively little over the lifetime.

${ }^{2}$ The link to evolutionary thinking is as follows: We do things that we enjoy. Evolution has designed us to enjoy things that are good for us. Declining enjoyment, therefore, is an index of declining fitness.

${ }^{3}$ This is because those young people who really did have no tomorrow are no longer around. Even if, on average, the young person was right to fear the future, those who did survive should believe their environment is relatively benign.
} 
aged people will discount least, with younger and older adults discounting more due (respectively) to uncertainty early in life and declining capacity late in life. Moreover, the effect of old age is greater than that of youth.

Figure 1 shows the values of $\delta$ estimated by the authors of the three models. These models all depend on making a variety of empirical and theoretical assumptions, so the precise values of $\delta$ are not directly comparable. The important distinction is in the predicted pattern of discounting. Based on plausible theoretical relationships between aging and time discounting, each model reaches different conclusions concerning how $\delta$ will change over the lifespan. In the present paper, we directly measure the time discounting of people throughout the lifetime to discover which, if any, of these patterns actually occurs.

-- Figure 1 about here --

\section{Previous experimental studies}

Green, Fry \& Myerson (1994) conducted a study of time discounting over the lifespan. They tested three groups of 12 participants: pre-teens (mean of $12 \mathrm{yrs}$ ), young adults (20 yrs), and older adults (67 yrs). They used a choice procedure to elicit discount rates for 8 delays and two amounts of money. From the observed choices they estimated the two parameters ( $k$ and $s$ ) in the following hyperbolic discount function, derived from Rachlin (1989):

$$
x_{0}=\frac{x_{i}}{\left(1+k t_{i}\right)^{s}} .
$$

Green et al. (1994) were mainly concerned with whether this functional form characterizes discounting over the lifespan. We will discuss their findings in more detail below, when we compare their results to ours. One of their observations, however, was that $\delta$ increases with age. Their preteens discounted more than young adults, who in turn discounted more than the elderly. This result, as it stands, appears consistent with the pattern predicted by Rogers (1984). It is not entirely consistent, however, since, as we discussed above, Rogers predicts that children will display a higher $\delta$ than will young adults, because they cannot yet transform resources into Darwinian benefits.

Green et al.'s pioneering study has several limitations. The most important of these is that their paper focused on incomparable samples. Their young adults were undergraduate college students, while their elderly sample was drawn from a university subject pool. There was no control of factors such as sex, income, health status and so forth, so we can only speculate about possible differences between groups that are unrelated to age. A second shortcoming is that they used only one class of discounting measure - what we will later call the SS-variable condition for money. Finally, their sample was quite small (12 per group) and therefore unlikely to yield a 'reliable' index of their population. Moreover, Green et al. did not include the middle-aged sample necessary for testing Sozou and Seymour's hypothesis. In our study we tested a larger sample (40 per group) of three age groups (young, middle-aged and elderly adults) and measured a wide range of relevant demographic factors as well as taking a number of different discounting measures.

After completing this manuscript we also learned of a study by Harrison, Lay \& Williams (2002), who conducted an experimental study of 268 Danes aged between 19 
and 75 years. They found, consistent with Green et al., that the discount factor was greatest for their 'old' sample. This old sample, however, was relatively young - it was defined as people aged 50 or greater, and they report no further breakdown of ages - and it is likely to be closer to an 'older middle age' group than to an elderly group such as that studied by Green et al. This finding remains consistent with Sozou and Seymour's view that the discount factor increases up to middle age and then drops off. Indeed, the small number of retired people in Harrison et al.'s sample had a lower discount factor than the rest of the sample ( $\delta=0.75$ versus $\delta=0.79$ ), and lower even than the average of the old sample $(\delta=0.8)$. Presumably, the retired sample were the more elderly of Harrison et al.'s old sample, suggesting that $\delta$ peaks somewhere in middle age and then falls. In the present study the average age of our elderly group was 75 (the maximum age in Harrison et al.'s sample) and so are likely to be like the retired subset of their old sample.

\section{Sample}

\section{Method}

Participants were 123 people aged between 19 and 89 (mean age 48.2) all either in employment (including homemakers) or retired. Sampling was done with the help of Age Concern (a UK charity concerned with the rights of the elderly) and local businesses who provided access to their employees and clients. We obtained a quota sample from three groups roughly defined as young (mean age 25), middle-aged (44) and elderly (75), with equal numbers of males and females in each group. The age distribution of these groups, for both males and females, is shown in Figure 2.

Table 1 gives a demographic breakdown of the three primary groups for several demographic variables. Although the potential significance of these factors for time preference will be discussed below, we can observe that the numbers reflect well-known social and demographic cross-sectional trends. Younger people are more likely to get a university education than older ones. People are more likely to have had children the older they get. Smoking is largely independent of age. People are much more likely to get a flu shot the older they are. Income (defined as yearly earnings) increases to middle age and then falls with retirement. Home ownership increases up to middle age, and then falls as elderly people exchange their houses for retirement homes.

-- Table 1 about here --

\section{Income and wealth}

Theoretically, wealth should be a major predictor of time discounting for money, with more wealth being associated with higher values of $\delta$. The reasons are manifold. First, wealthier people are unlikely to need immediate cash, and so are more able to wait to get more, and they will also typically have access to more favorable lending rates. Moreover, more patience may be a cause of greater wealth, with patient people by definition being willing to wait for larger-later rewards (Mischel, Shoda \& Rodriguez, 1989). We have already indicated that our young and (especially) elderly sample had lower incomes than did the middle-aged one. We wished to ensure that this was fully accounted for in our analyses, so we included a further proxy of income and overall social status in our measures: the kind of neighbourbood in which they lived. In the UK 
this is given by the ACORN (A Classification Of Residential Neighbourhoods) classification which assigns to each post-code in the UK a category number corresponding to the lifestyle and demographic characteristics of our residents. There are 54 ACORN types that are further subdivided into 17 groups. We obtained post-codes from our participants and used these to assign them to their ACORN types and groups. To facilitate analysis, we further collapsed the 17 groups into 6 clusters that fit together. Without going into detail about ACORN classifications (see www.caci.co.uk), we can summarize these clusters as follows:

A (Including group 1): Wealthy achievers mostly in suburban areas.

$\mathrm{B}$ (Groups 2 to 6): Affluent home-owning families in both urban and rural areas.

$\mathrm{C}$ (Groups 7 to 8): Professionals living in metropolitan areas.

D (Groups 9 to 11): Middle to working class

E (Groups 12 to 14$)$ : Working class

F (Groups 15 to 17): Poor living in council estates and inner cities.

The table shows the proportion in each cluster for the three age groups in our sample, and for the UK as a whole. Because our sampling was done around Leeds and London, our sample contains a disproportionate number of urban dwellers in A and F relative to the UK as a whole. Moreover, and unsurprisingly, elderly people were more likely to be found living in the poorer neighborhoods than were other groups.

-- Table 2 about here --

\section{Health status}

One's state of health can be reflected in discounting in two ways. First, poor health is an indicator of mortality, and will therefore increase one's uncertainty about whether future rewards will be received. Second, poor health may indicate decreasing pleasure from experience. Someone with a chronic disease, for instance, may prefer money or holidays as soon as possible, because if he or she waits it may no longer be possible to enjoy them.

We included four measures of health and health-related behavior. Two of these, whether people were current smokers or had a recent flu shot, were already discussed above. We also asked 'How would you characterize your current health?' which was answered on a 5-point scale ranging from Extremely good to Extremely bad. We also asked participants to indicate if they suffered from any long-term health problems. Not surprisingly, the prevalence of such problems increased with age: $13 \%$ of young people, $27 \%$ of middle-aged and $67 \%$ of the elderly reported them.

\section{Computerised instrument}

The computerized part of the study was an adaptation of one described by Read (2001; Read \& Roelofsma, 2003). All questions involved a choice between a larger-later (LL) and smaller-sooner (SS) amount of money. The amounts were presented on a computer screen in the following way:
Amount:
$£ 600$
$£ 1200$

When received: $\quad$ Sept 28, 2003

Sept 27, 2004 
Participants indicated, by pressing a key, which option they would choose, after which one amount was adjusted up or down, depending on the option chosen. In half the questions the adjusted amount was SS, while in the remainder it was LL: if the fixed amount was LL the SS amount would be increased following a choice of LL, or decreased following a choice of SS; while if the fixed amount was SS the LL amount would be increased following a choice of SS, or decreased following a choice of LL. With each choice the difference between the two amounts was reduced until an indifference point, calculated to the nearest multiple of $£ 5$, was reached.

In this way we obtained indifference points over 8 different time spans: $0 \rightarrow 1$ year; $0 \rightarrow 2$ years; $0 \rightarrow 3$ years; $1 \rightarrow 2$ years; $2 \rightarrow 3$ years; $0 \rightarrow 10$ years; and, $7 \rightarrow 10$ years. Each time span was repeated twice, once with SS-variable and one with LL-variable.

The fixed value of SS was $£ 600$ (i.e., participants decided whether a larger amount at the end of the time span was more or less valuable than $£ 600$ at the beginning) and the fixed value of LL was $£ 1200$. The questions were given in random order, subject to the stipulation that questions about the same time span were separated by at least one question. Each session started with practice sequences that familiarized participants with the task, followed by test sequences.

Once an indifference point had been reached through the choice titration procedure, participants could indicate whether they agreed or disagreed with the indifference points generated and, if they disagreed, to repeat the sequence.

\section{Questionnaire}

The questionnaire contained those questions about demographic factors already discussed and two questions about time preference. These concerned discounting for non-monetary goods, holidays or bouts of flu. They were included to find out whether our results could be generalized to non-fungible or experience goods.

In the holiday question participants decided about a trade-off between a shortersooner holiday or a longer-later one:

Imagine you have won a 21 day holiday for two, all expenses paid, to Barcelona. Unfortunately, you will not be able to take this holiday until Summer 2006 [Three years from the date of the questionnaire]. Nevertheless, you do have the option of taking a free holiday this coming summer [2003] instead. The 2003 holiday will be identical to the 21 day holiday in 2006 in every respect except its length.

The choice was presented in a table with each line offering two options, such as:
1 day in 2003
-or-
21 days in 2006
2 days in 2003
-or-
21 days in 2006

On each line, participants indicated whether they would take the earlier or later holiday. In the flu question, based on a question used by Chapman et al. (2001), participants chose between a sooner or later illness:

Imagine that you get the flu one year from now (next August). You feel so week and achy that you can't get out of bed. You have a high fever, a sore throat, and 
persistent painful cough. You sneeze and your nose is runny and stuffy. Your flu would last for 10 days.

If you could choose, would you prefer to have this 10-day bout of flu next year, or a shorter bout of flu this August?

As with the holiday question, participants made 10 choices between an $n$-day flu immediately or a 10-day flu in one year.

\section{Results}

Analyses were conducted using multiple regression. We first describe our dependent and independent variables before turning to the analyses.

\section{Dependent variables}

For each question, a value of $\delta$ was obtained using Equation 1. For the computerized questions, analysis was conducted on aggregate values of $\delta$, obtaining by averaging individual values for related time spans. The three measures varied in the length of the interval over which discounting occurred, and when the interval began. The first aggregate $\delta$, which we call $\delta(\leq 3)$, is the mean $\delta$ for all time spans ending within three years of the time of testing. That is, we combined $\delta(0 \rightarrow 1), \delta(0 \rightarrow 2), \delta(0 \rightarrow 3)$, $\delta(1 \rightarrow 2)$ and $\delta(2 \rightarrow 3)$ when both SS and LL were adjusted. These are roughly the kinds of intervals over which the typical study of time preference is conducted. They are also the shortest intervals over which any of the aging theories have something to say, since they all concern events that take place over years rather than days (such as changes in the ability to enjoy consumption, changes in fertility, and in the probability of dying). The second aggregate was $\delta(0 \rightarrow 10)$ which combined both the SS- and LL-variable measure for that time span. This period was long enough that the possibility of death or serious impairment was substantial for our elderly sample. The third aggregate was $\delta(7 \rightarrow 10)$ which covered approximately the same interval length as $\delta(<3)$. We also obtained two discount factors from the questionnaire, one for the flu and the holiday question. These values of $\delta$ (Holiday) and $\delta($ Flu) were subject to separate analysis.

\section{Independent variables}

The independent variables were all the demographic measures taken from the questionnaire. These are, with one exception, self-explanatory:

Age (in years)

Z-Age-squared

Sex

Income (A 6-point ordinal variable)

Education $(0=$ no university; $1=$ university)

Children $(0=$ no children; $1=$ children $)$

Health $(0=$ good health; $1=$ poor health $)$

Disease $(0=$ no; $1=$ yes $)$

Flu shot $(0=$ no; $1=$ yes $)$

Home Ownership $(0=\mathrm{No} ; 1=$ Yes $)$

Acorn group (5 dummy variables corresponding to cluster A, B, C, D, E) 
The variable Z-Age-Squared is the negative of each participant's z-score for age, as depicted in Figure 1. We included this variable so we could test Sozou and Seymour's (2003) prediction of a curvilinear relationship between age and discounting. Their theory suggests there will be a positive coefficient for this variable (higher values of Z-AgeSquared will be associated with higher values of $\delta$ ).

\section{Multicollinearity}

Some of our demographic measures are correlated with age, so the potential problem of multicollinearity is a real one. We tested for this using the methods suggested by Stevens (1996). First, we looked at the zero order correlation between all independent variables. While there were many significant correlations, none were particularly high. Only three reached or exceeded 0.5 (between age and income; age and flu shot; and education and income). Second, we looked at the variance inflation factors (VIFs), which indicates whether there is a strong linear association between each predictor and all remaining predictors. Stevens, following Myers (1990), suggests that we should be concerned if we find a VIF exceeding 10. For our data, no VIF exceeded 3, and the great majority were less than 2 . We concluded, therefore, that there was no reason to be concerned about multicollinearity.

$$
\text { -- Figure } 3 \text { about here -- }
$$

\section{Analyses}

Table 3 shows the mean and median values of $\delta$ for all age groups. As can be seen, the computer derived values show the pattern suggested by Sozou and Seymour (2003) of a highest $\delta$ amongst the middle-aged, and a lowest $\delta$ amongst the elderly. The $\delta$ (holiday) and $\delta$ (flu) estimates, however, show different patterns: $\delta$ (holiday) declines with age, while $\delta(\mathrm{flu})$ increases. We will consider these patterns along with the regression analyses.

-- Table 3 about here --

We conduct the regression analyses in two stages. First, we regress discounting from Age and Z-Age-Squared alone, and then conduct a full regression including all independent variables to determine the degree to which any observed effects are attenuated by adding predictors that are partly correlated with Age and Z-Age-Squared. The results of the reduced analysis are given in Table 4, and those of the full analysis are given in Table 5. A glance at these tables, which mark significant results with asterisks, shows that the two Age variables are the most important predictors of discounting, although not in all conditions. 


\section{$\delta(\leq 3)$}

Given the pattern of means shown in Table 3 , it is unsurprising that the age-only regression analysis revealed no effect of Age and only a marginal effect of Z-AgeSquared. In the full analysis the only significant effect was that of sex, with the $\delta$ for women exceeding that for men.

We speculate that one important issue is that, in the relatively short term, even the elderly do not anticipate that they might not live to see the money, so there is not much uncertainty about its receipt. Based on government life tables, the eldest of our respondents had a life expectancy of slightly over 4 years. Thus, one of the major factors for discounting may play a lesser role over the time span embraced by these measures.

\section{$\delta(0 \rightarrow 10)$ and $\delta(7 \rightarrow 10)$}

These items were designed to elicit attitudes toward the relatively distant future. It is natural to expect that the elderly will be particularly sensitive to such long delays, since there is a very real risk that they will not be around to achieve the rewards at the end of them - half of our elderly sample had a life expectancy of less than 10 years. Moreover, Trostel and Taylor's (2001) analysis would predict an enhanced effect of Age for both these questions, since they span those periods where the greatest decline in the ability to appreciate consumption is likely to occur. Consistent with this, these questions showed the strongest age effects. In the age-only analysis, both Age and Z-Age-Squared were significantly related to $\delta$. In the larger analysis, other variables mopped up some of the variance explained by age, with only Z-Age squared (for $\delta(0 \rightarrow 10)$ ) and Age (for $\delta(7 \rightarrow 10))$ remaining significant. Two factors became particularly important here, Education and where one lived: more educated people discounted less, as did those who lived in the wealthy A Clusters. These variables are themselves associated with age, with the elderly more likely to live in poor areas and to be less educated.

\section{$\delta$ (holiday) and $\delta$ (flu)}

These questions asked people to make discounting decisions about concrete and non-fungible outcomes ${ }^{4}$. The age-only analysis showed that discounting was related to age, in that older people discounted holidays less than younger ones, and this relationship was upheld by the larger analysis.

The age effect for $\delta$ (flu) was weaker and in the opposite direction - both analyses showed a weak tendency for increasing age to be associated with a higher value of $\delta$. The analysis of $\delta(\mathrm{flu})$ also revealed a significant influence of several ACORN clusters. A closer inspection of $\delta(\mathrm{flu})$ as a function of the various clusters, shown in Table 6 , shows considerable, but non-systematic, variability: Clusters A, C and F are associated with higher average values of $\delta(\mathrm{flu})$. We cannot interpret this pattern and suggest it may be a chance occurrence.

-- Table 6 about here --

\footnotetext{
${ }^{4}$ A fungible good is one that can be stored, traded and invested. Money is the ultimate fungible good, but most things have some element of fungibility. A non-fungible good is something that cannot be traded. Health is probably the best real world example, although complete non-fungibility may not exist - it is possible to store future health by a healthy lifestyle, and to squander it with an unhealthy one.
} 
It is useful to consider the contrast between the flu and holiday results from the perspective of Trostel and Taylor's (2001) account of aging and discounting. The elderly appear to discount holidays more than the young, and to discount the flu less. However, suppose, as Trostel and Taylor do (and I suspect we might all agree) that as we age we become increasingly vulnerable to illness, and increasingly less able to enjoy a holiday. That is, both a flu and a holiday next year are worse than one this year. The effect of this will be to make us more impatient about holidays (we want even a short one now rather than a longer one later) and more patient about the flu (we want even a long one now over a shorter one later). This is what we have observed in our data.

\section{Comparison with Green, Fry and Myerson (1994)}

Green et al (1994) suggested that young adults discounted more than elderly ones. We found no evidence of this, and actually observed evidence of greater discounting by the elderly, and also of an inverted-U relationship in which middle aged people discounted less than both the elderly and the young. It is not immediately evident where the difference lies in the two studies. While the methods differ, they do not differ by much. We used a titration procedure, while Green et al. used a closely-related crossover point procedure like that used in our holiday and flu questions. We suggest that the most likely explanations are either that (a) their two samples were drawn from different populations, and (b) their sample of young adults was actually younger than ours, and the intervening years may have led to an increase in patience. However, as we show in this section, there are some striking similarities between their results and ours.

The primary goal of Green et al.'s study was to test the version of hyperbolic discounting earlier proposed by Rachlin (1989), and which we introduced above as Equation 2. The corresponding value of $\delta$ is as follows:

$$
\delta\left(0 \rightarrow t_{2}\right)=\left(1+k t_{2}\right)^{-s / t_{2}} \text {. }
$$

Green et al. described $k$ as the rate of discounting and $s$ as a measure of sensitivity to delay, although both parameters actually contribute to discounting in a monotonic fashion - higher values of both $s$ and $k$ mean lower values of $\delta$. Moreover, when $s$ is high and $k$ is low, this function approaches exponential or constant rate discounting, meaning that $\delta$ is the same over all same-length periods and there is no bias in favor of immediate receipt $^{5}$. Green et al. concluded that their function provided an excellent fit to their median discount rates.

We can compare our results to Green et al.'s by fitting Equation 3 to our data, and by comparing their parameter estimates to ours. Table 7 shows the two parameters estimated by Green et al., and estimated by us from our data. We used four of our computerized discount factors to make these estimates $[\delta(0 \rightarrow 1), \delta(0 \rightarrow 2), \delta(0 \rightarrow 3)$ and $\delta(0 \rightarrow 10)$ ] while Green et al. used eight. As can be seen in Table 7, the values of $k$ and $s$ are very similar across the two studies for the two overlapping groups. Apart from the numeric similarity, the qualitative relationships are striking: the $k$ parameter is considerably higher for young adults than for the elderly, and the $s$ parameter is much less than 1 for the young and much more than 1 for the elderly. The net implication of

\footnotetext{
${ }^{5}$ Rachlin's function is closely related to the generalized hyperbolic discount function proposed by Loewenstein and Prelec (1992). Like that function it approximates classic hyperbolic discounting when $\mathrm{k}$ is positive and $\mathrm{s}$ is close to 1 , and exponential discounting when $\mathrm{k}$ is very small and $\mathrm{s}$ is very large.
} 
the two parameters is that the young adults in both studies show the 'hyperbolic' discounting effect of an increasing value of $\delta$ the longer the delay, while the elderly samples show more-or-less constant or 'exponential' discounting.

-- Table 7 about here --

In Figure 4 we plot the mean values of $\delta$ from our study, the best fitting model fit to those values, and the corresponding values inferred from Green et al's model. Two things are clear. First, while Green et al.'s elderly subjects had higher values of $\delta$ than did their young adults, our young adults generally had higher values of $\delta$ than our elderly. Despite this difference, however, the shape of the curve showing how $\delta$ changes with increasing delay is very similar for the two young and old groups in both studies.

-- Figure 4 about here --

In sum, therefore, Green et al.'s major result - that younger people show hyperbolic discounting while older people show exponential discounting - is supported by our data. Moreover, a function of the same shape as that proposed by Green et al. also fit our data approximately as well did their function.

\section{Conclusion}

Theoretical descriptions of why people discount the future often predict differences in the rate of that discounting over the lifespan. To examine these claims we measured discount factors $(\delta)$ for several contexts and delays in people of various ages. We observed systematic but relatively complex relationships between discounting and age. The major trends were for the elderly to discount the most (lower $\delta$ ), and for the middle-aged to discount less than either the elderly or the young. The effects were particularly strong for discounting over long delays, and for holidays. The overall pattern of discounting matches that predicted by Sozou and Seymour (2003) with patience increasing until middle age, at which point it falls. Sozou and Seymour attribute the latelife fall to a decline in fertility and mating opportunities, while Trostel and Taylor (1981) attribute it to the fact that as people age they view the prospect of getting pleasure out of future consumption to be increasingly less likely, and so want to get as much pleasure as they can by consuming now. These are not independent effects, but we find Trostel and Taylor's position to be particularly persuasive. Declining fertility is unlikely to be an issue for all but a handful of our elderly participants, so it cannot predict an increase in the age effect for long delays and for the distant future $((\delta(0 \rightarrow 10), \delta(7 \rightarrow 10))$. Moreover, as discussed above, the age effects for $\delta$ (holiday) and $\delta$ (flu) can readily be understood from the perspective of Trostel and Taylor's theory.

Our data did not appear to support Rogers' theory, which predicts that discounting will be greatest for the young and higher for all older groups, especially over the relative short term represented by $\delta(\leq 3)$. We believe, however, that in this respect our results offer a call to future research, because there is some question concerning how we can interpret our data. As we mentioned above, much of the work in Rogers' theory is done by people choosing to transfer resources, either to their future selves or even to other generations. This can only occur for fungible goods, such as money, but not holidays or 
health. Our money discounting questions, therefore, would seem like the proper test of Rogers theory. However, researchers into time preference usually assume that people treat money as if it was a non-fungible good like health or happiness (Read, in press). There are some good empirical reasons for doing so: when discussing intertemporal monetary trade-offs people often do not consider the possibility that they can invest the money they have now, or borrow on money they will get in the future. Rather, they assume they will spend money as and when they receive it (Read \& Powell, 2002). If people do not treat money as fungible, then Rogers' theory may not be applicable to our results. This is not an entirely satisfactory conclusion, however, because if people do not treat money as fungible, any theory that assumes they do will be based on a false premise. We conclude, therefore, that while our data puts a question mark beside Rogers' theory, it cannot be said to absolutely refute it.

Our results also appear to contrast with the well-founded stereotype of young people as being overwhelmingly impatient, a stereotype bolstered by the fact that teenagers and young adults are much more likely to engage in such impulsive and reckless behaviors as crime, unsafe sex and even nightclubbing when they should be studying. But it is not necessary, and perhaps even implausible, to attribute impulsive behavior to a low discount factor. There are many differences between younger and older people that can produce this difference. One, of course, is the ability to successfully carry out a desired act - older people may be less likely to commit crime because they lack the energy to do so and are more likely to get caught. But independent of this factor impulsive and apparently short-sighted behaviour has two components. First, there is the relative preference between smaller-sooner and larger-later outcomes. This is the domain of time preference proper, as investigated in this paper. We might commit more crime when young because we value the immediate fruits of crime more than they delayed ones of honesty. Second, there is the ability to implement a far-sighted preference in the face of temptation. A young person may want to stay home and study even more than a middle aged man wants to stay home and write, but the young one may not be able to resist the temptation to go out, while the older one can. Much theoretical discussion of the development of patience actually concerns this second influence on impulsiveness. Mischel and his colleagues, for example, in their investigation of how children become able to resist temptation, emphasize the acquisition of cognitive strategies and not the development of a high value of $\delta^{6}$. In short, our results cannot be interpreted as saying that young adults are relatively patient, in the sense of not being impulsive, but only that they are relatively patient in the sense that in a cool moment if they think seriously about whether it is better to have A sooner or B later, they are more likely than an older adult to agree it is better to wait for B. And, as suggested both by common sense and by the analyses of Trostel and Taylor (2001) and Sozou and Seymour (2003), both the young and the old are probably correct in their assessments.

\footnotetext{
${ }^{6}$ Ironically, Mischel's work shows that valuing future outcomes more can act against patience. Children who set their sights on a remote goal of two cookies become very impatient for one cookie now. It is often by forgetting about the future that they learn to be patient (Mischel, Ayduk \& Mendoza-Denton, 2003).
} 
Author notes: We are indebted to Grainne Schmid for providing sterling research support and invaluable discussion, and to Peter Sozou for helping us understand the aging literature. We also thank the many people at Age Concern (Leeds and Southwark), the Medical Devices Agency, the One O'Clock Playrooms in Southwark Park and Peckham Rye. The research was funded by the STICERD foundation, and by ESRC Research Grant RES-000-22-0201. 


\section{References}

Chapman, G. B., Brewer, N. T., Coups, E. J., Brownlee, S., Leventhal, H., \& Leventhal, E. A. (2001). Value for the future and preventive health behavior. Journal of Experimental Psychology: Applied, 7, 235-250.

Fisher, I, (1930). The theory of interest. New York: Macmillan.

Frederick, S., Loewenstein, G., \& O’Donoghue, T. (2003). Time discounting and time preference: A critical review. In Loewenstein, G., Read, D. \& Baumeister, R. F. (Eds). Time and decision; Economic and psychological perspectives on intertemporal choice. New York: Russell Sage Foundation.

Freud, Sigmund. 1911/1959. Formulations regarding the two principles of mental functioning. Collected Papers, Vol. IV. New York: Basic Books.

Green, L., Fry, A. F., \& Myerson, J. (1994). Discounting of delayed rewards: A life-span comparison. Psychological Science, 5, 33-36.

Metcalfe, J., \& Mischel, W. (1999). A hot/cool system analysis of delay of gratification. Psychological Review, 106, 3-19.

Mischel, W. (1974). Processes in delay of gratification. Advances in Experimental Psychology, 7, 249-292.

Mischel, W., Ayduk, O., \& Mendoza-Denton, R. (2003). Sustaining delay of gratification over time: A hot-cool systems perspective. In Loewenstein, G., Read, D., \& Baumeister, R. F. (Eds). Time and Decision: Economic and psychological perspectives on intertemporal choice. New York: Russell Sage Foundation.

Mischel, W., Shoda, Y \& Peake, P. (1988). The nature of adolescent competencies predicted by preschool delay of gratification. Journal of Personality and Social Psychology, 54, 687-696.

Mischel, W., Shoda, Y. \& Rodriguez, M. L. (1989). Delay of gratification in children. Science, 244, 933-938.

Rachlin, H. (1989). Judgment, decision, and choice: A cognitive/behavioral synthesis. New York: Freeman.

Read, D. (2001) Is time-discounting hyperbolic or subadditive? Journal of Risk and Uncertainty 23, 5-32.

Read, D. (In press). Intertemporal choice. In Koehler, D. \& Harvey, N. (Eds.) The Blackwell Handbook of Judgment and Decision Making. Oxford: Blackwell.

Read, D. and Powell, M. (2002). Reasons for Sequence Preferences. Journal of Behavioral Decision Making, 15, 433-460.

Read, D. \& Roelofsma, P. H. M. P. (2003). Subadditive versus hyperbolic discounting: A comparison of choice and matching. Organizational Behavior and Human Decision Processes, 91, 140-153.

Rogers, A. R. (1994). Evolution of time preference by natural selection. American Economic Review, 84, 460-481.

Sozou, P. D. \& Seymour, R. M. (2003). Augmented discounting: interaction between aging and time-preference behavior. Proceedings of the Royal Society of London $B$ 270, 1047-1053.

Strotz, R H. (1955). Myopia and inconsistency in dynamic utility maximization. Review of Economic Studies, 23, 165-180. 
Trostel, P. A., \& Taylor, G. A. (2001). A theory of time preference. Economic Inquiry, 39(3), 379-395. 
Table 1: Description of population according to selected demographic variables.

\begin{tabular}{|c|c|c|c|c|c|c|}
\hline Group & University & Children & $\begin{array}{l}\text { Current } \\
\text { smoker }\end{array}$ & $\begin{array}{c}\text { Recent flu } \\
\text { shot }\end{array}$ & $\begin{array}{c}\text { Income } \\
(£ 000)\end{array}$ & $\begin{array}{l}\text { Home } \\
\text { owner }\end{array}$ \\
\hline Young & $30 \%$ & $18 \%$ & $28 \%$ & $8 \%$ & 16 & $20 \%$ \\
\hline Middle Aged & $22 \%$ & $63 \%$ & $28 \%$ & $18 \%$ & 20 & $68 \%$ \\
\hline Elderly & $0 \%$ & $86 \%$ & $26 \%$ & $71 \%$ & 8 & $48 \%$ \\
\hline
\end{tabular}

Table 2: Description of population according to ACORN cluster.

\begin{tabular}{lrrrrrrr}
\hline & \multicolumn{7}{c}{ ACORN cluster } \\
& \multicolumn{1}{c}{ A } & \multicolumn{1}{c}{ B } & C & D & E & F \\
\hline Young & $3 \%$ & $8 \%$ & $45 \%$ & $10 \%$ & $15 \%$ & $20 \%$ \\
Middle & $10 \%$ & $7 \%$ & $27 \%$ & $17 \%$ & $24 \%$ & $15 \%$ \\
Old & $14 \%$ & $5 \%$ & $17 \%$ & $14 \%$ & $14 \%$ & $36 \%$ \\
\hline UK & $15 \%$ & $19 \%$ & $6 \%$ & $34 \%$ & $19 \%$ & $7 \%$ \\
\hline
\end{tabular}

Table 3: Mean and median discount factors for three age groups

\begin{tabular}{|c|c|c|c|c|}
\hline & & \multicolumn{3}{|c|}{ Age groups } \\
\hline & & Young & Middle Aged & Elderly \\
\hline \multirow[t]{2}{*}{$\delta(\leq \mathbf{3})$} & Mean & .70 & .76 & .67 \\
\hline & Median & .72 & .79 & .76 \\
\hline \multirow[t]{2}{*}{$\delta(0 \rightarrow 10)$} & Mean & .82 & .89 & .70 \\
\hline & Median & .87 & .90 & .82 \\
\hline \multirow[t]{2}{*}{$\delta(7 \rightarrow 10)$} & Mean & .81 & .83 & .62 \\
\hline & Median & .83 & .88 & .73 \\
\hline \multirow[t]{2}{*}{$\delta$ (holiday) } & Mean & .78 & .73 & .64 \\
\hline & Median & .78 & .78 & .69 \\
\hline \multirow[t]{2}{*}{$\delta($ flu $)$} & Mean & .63 & .67 & .74 \\
\hline & Median & .50 & .70 & .80 \\
\hline
\end{tabular}


Time discounting over the lifespan

Page 21

Table 4: Age-only analysis for all discount factors.

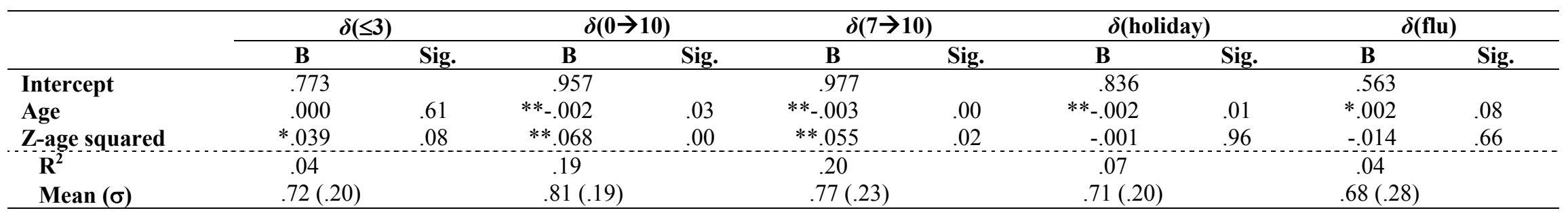


Time discounting over the lifespan

Page 22

Table 5: Full regression analysis for all discount factors.

\begin{tabular}{|c|c|c|c|c|c|c|c|c|c|c|}
\hline & \multicolumn{2}{|c|}{$\delta(\leq 3)$} & \multicolumn{2}{|c|}{$\delta(0 \rightarrow 10)$} & \multicolumn{2}{|c|}{$\delta(7 \rightarrow 10)$} & \multicolumn{2}{|c|}{$\delta$ (holiday) } & \multicolumn{2}{|c|}{$\delta($ flu $)$} \\
\hline & B & Sig. & B & Sig. & B & Sig. & B & Sig. & B & Sig. \\
\hline Intercept & .525 & & .763 & & .708 & & .647 & & .746 & \\
\hline Age & .000 & .96 & -.002 & .22 & $*_{-} *_{-.004}$ & .01 & $*_{-} *_{-.003}$ & .03 & $* .003$ & .09 \\
\hline Z-age squared & .038 & .17 & $* * .058$ & .02 & .026 & .36 & -.001 & .99 & .043 & .26 \\
\hline Sex & $* * .113$ & .01 & .047 & .19 & .069 & .10 & .023 & .58 & .068 & .23 \\
\hline Education & -.018 & .77 & -.052 & .33 & .023 & .72 & -.092 & .14 & -.022 & .52 \\
\hline Children & -.039 & .43 & -.008 & .85 & .023 & .72 & -.017 & .73 & .064 & .44 \\
\hline Health & -.025 & .42 & -.004 & .88 & .029 & .57 & $* .057$ & .07 & -.017 & .80 \\
\hline Disease & -.007 & .88 & -.040 & .33 & -.005 & .87 & -.071 & .14 & -.069 & .12 \\
\hline Flu shot & .074 & .18 & .021 & .65 & .001 & .99 & .041 & .45 & .052 & .43 \\
\hline Income & .040 & .12 & $* .042$ & .07 & $* .047$ & .08 & .020 & .44 & -.022 & .52 \\
\hline Home & .009 & .84 & .023 & .57 & .059 & .21 & .020 & .66 & -.078 & .22 \\
\hline $\mathbf{A}$ & .060 & .45 & $* * .146$ & .04 & *.133 & .10 & .121 & .13 & -.034 & .76 \\
\hline B & .043 & .61 & .045 & .53 & .020 & .81 & .108 & .20 & $* *-.259$ & .02 \\
\hline C & .019 & .71 & .032 & .49 & .002 & .98 & .035 & .51 & -.005 & .94 \\
\hline D & .030 & .67 & .079 & .19 & .066 & .35 & .009 & .90 & $* *-.199$ & .04 \\
\hline $\mathbf{E}$ & .061 & 31 & .027 & 60 & .054 & .38 & .095 & .11 & $* *-171$ & .04 \\
\hline $\mathbf{R}^{2}$ (Adjusted) & $.16(.04)$ & & $.30(.20)$ & & $.33(.24)$ & & $.17(.04)$ & & $.19(.07)$ & \\
\hline
\end{tabular}


Table 6: Delay discounting $\delta(f l u)$ as a function of ACORN Cluster

\begin{tabular}{lccccccc}
\hline & \multicolumn{7}{c}{ ACORN Cluster } \\
Age group & A & B & C & D & E & F \\
\hline Young & 0.50 & 0.43 & 0.71 & 0.60 & 0.47 & 0.68 \\
Middle Aged & 0.73 & 0.63 & 0.69 & 0.49 & 0.69 & 0.86 \\
Elderly & 0.83 & 0.50 & 0.90 & 0.62 & 0.53 & 0.82 \\
\hline Mean & 0.69 & 0.52 & 0.77 & 0.57 & 0.56 & 0.79 \\
\hline
\end{tabular}

Table 7: Comparison of discounting parameters obtained by Green et al. (1994) and in the present study.

\begin{tabular}{lccrr}
\hline & \multicolumn{2}{c}{ Green et al. (1994) } & \multicolumn{2}{c}{ This study } \\
\cline { 2 - 5 } & $\boldsymbol{k}$ & $\boldsymbol{s}$ & $\boldsymbol{k}$ & $\boldsymbol{s}$ \\
\hline Children & .618 & .368 & .076 & .516 \\
Young adults & .075 & .724 & .120 & .289 \\
Middle aged & & & .001 & 15.401 \\
Elderly & .002 & 5.01 & & \\
\hline
\end{tabular}




\section{Figure captions}

Figure 1: Patterns of time discounting over the lifespan as predicted by Rogers (1994), Trostel and Taylor (2001) and Sozou and Seymour (2003).

Figure 2: Box plot showing age distribution of three groups of participants divided by sex. The line in the box is the median, the box gives the interquartile range (including $50 \%$ of values), and the whiskers give extreme values.

Figure 3: Z-Age squared. This variable is used to test the hypothesized curvilinear relationship between age and discounting.

Figure 4: Comparison of $\delta$ for delays of different length. The lines labelled 'Green' show results predicted from the best-fitting functions described by Green et al. (1994). The shapes (circles, triangles, squares) show data collected in the present study, along with their associated best-fitting line. 
Time discounting over the lifespan

Page 25

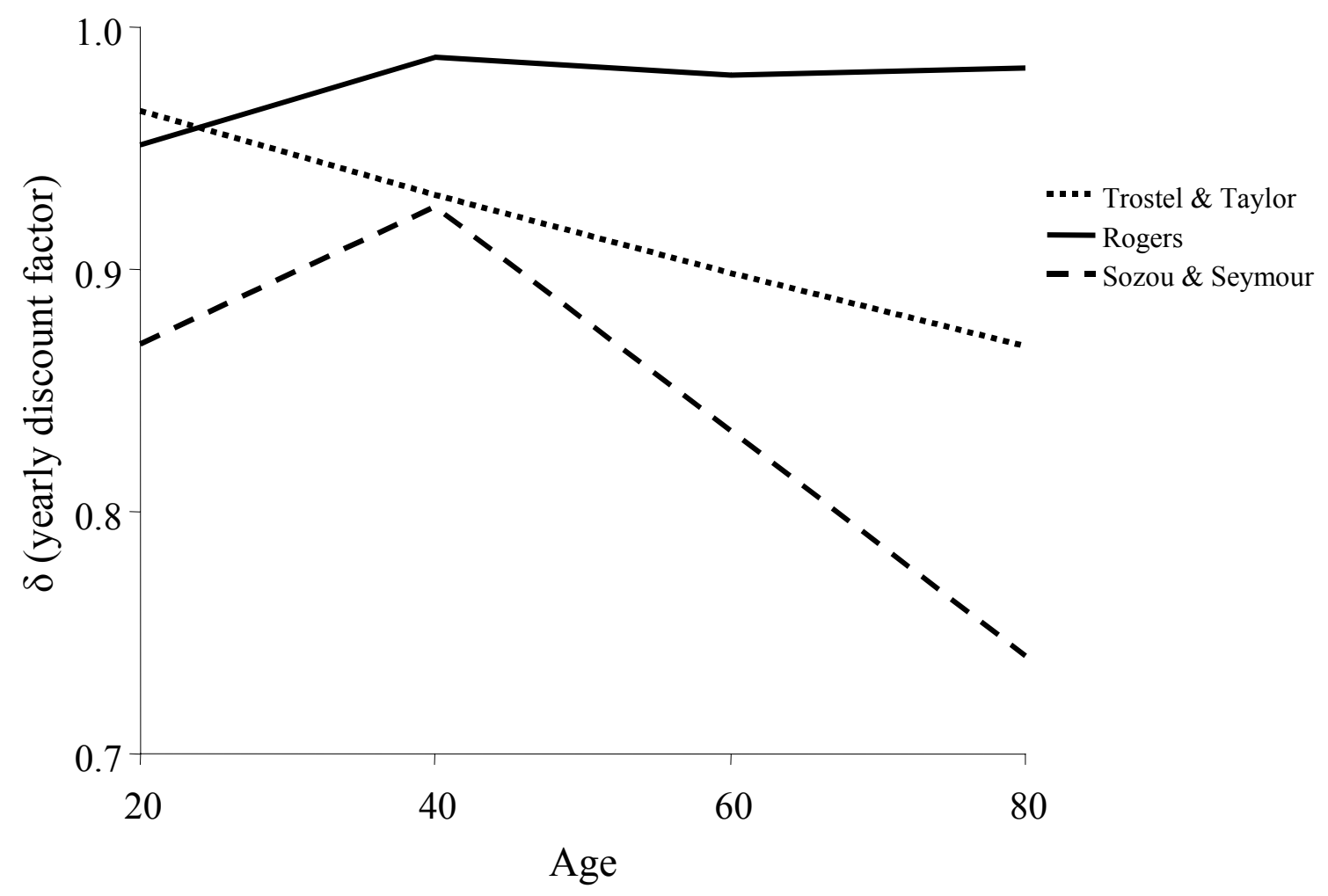


Time discounting over the lifespan

Page 26

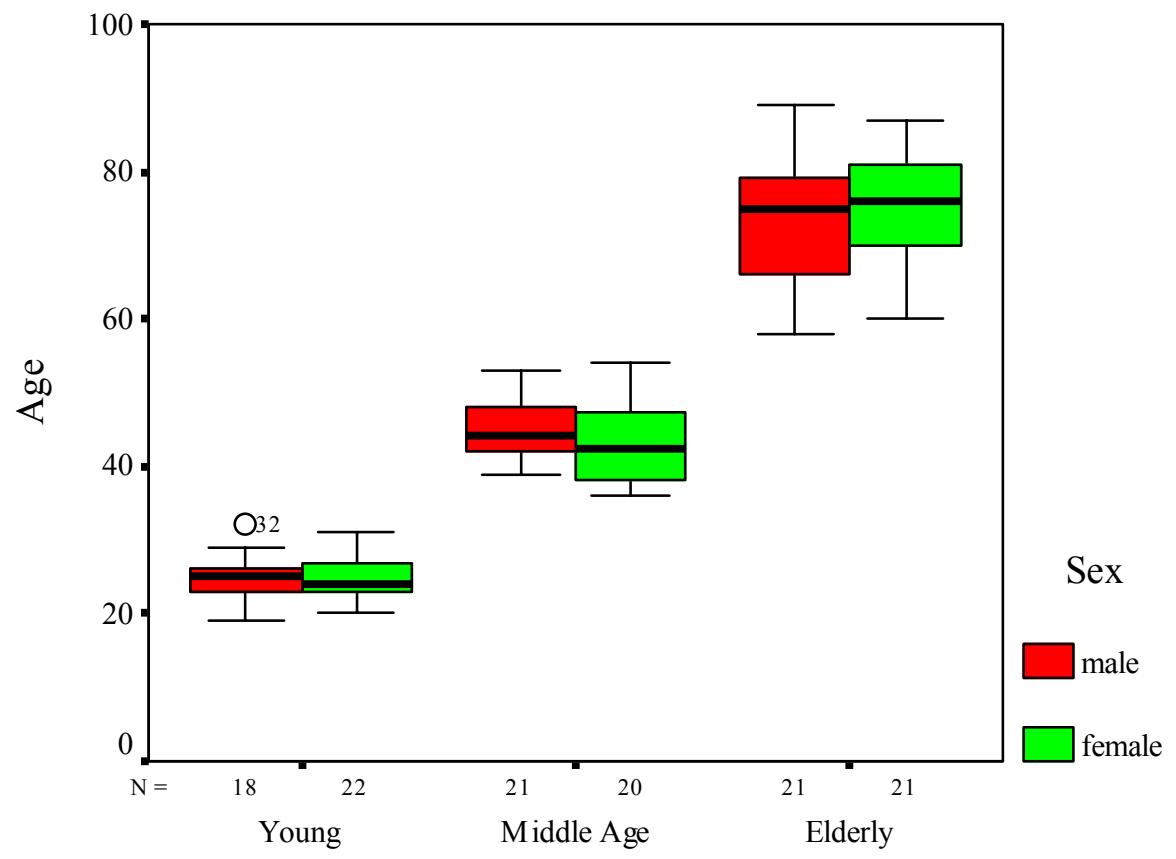

Age group 
Time discounting over the lifespan

Page 27

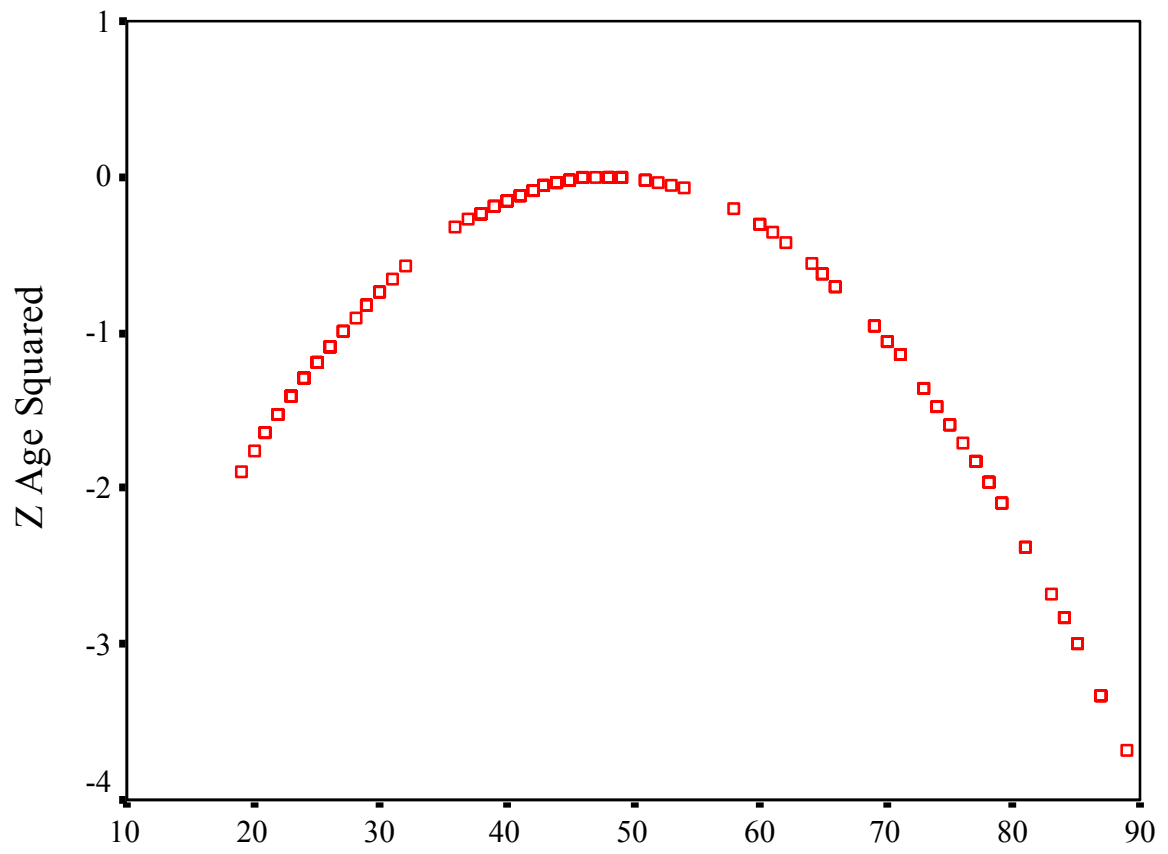

Age 


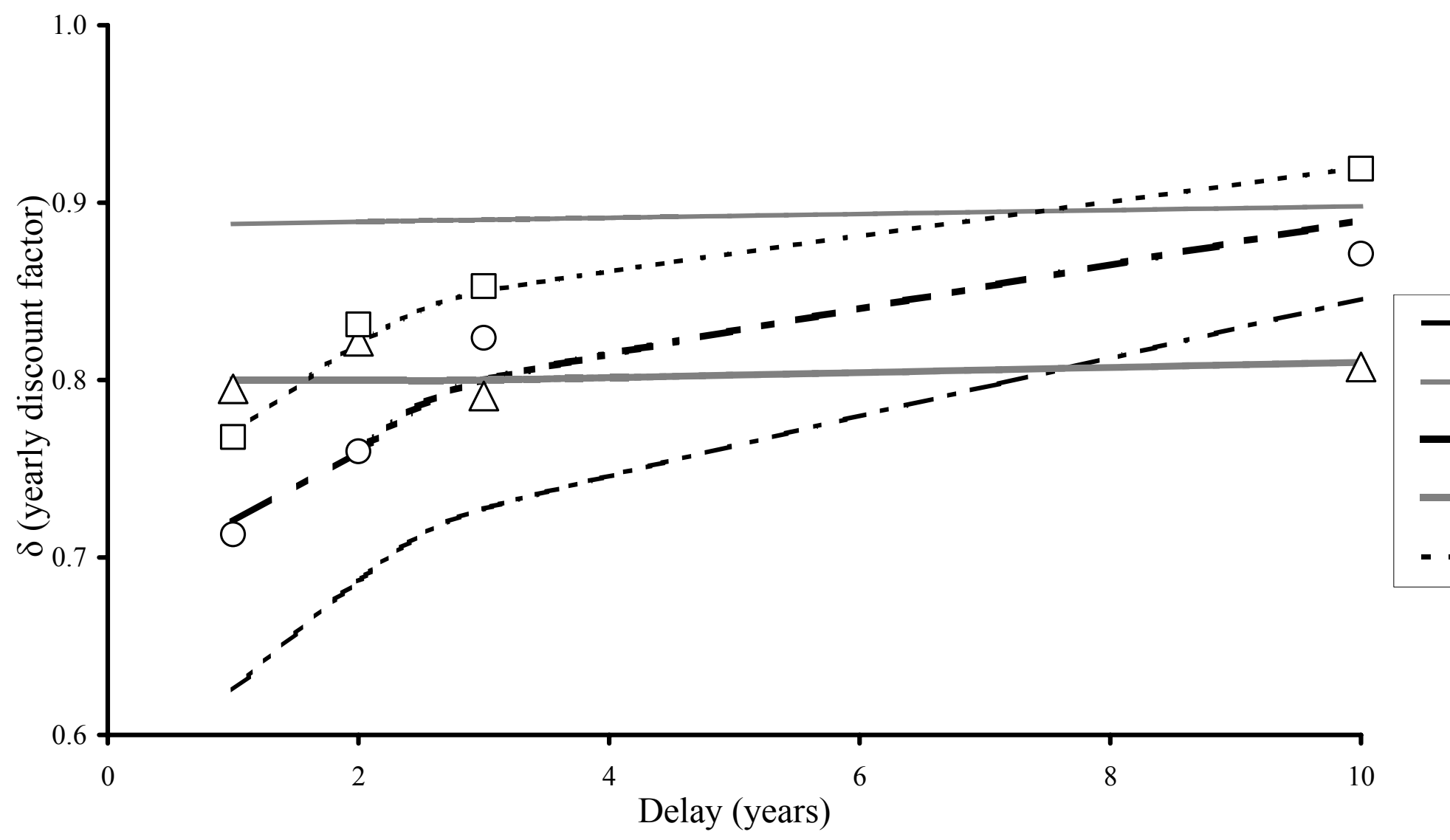

